\title{
The Effect of Fabrication Conditions for GDC Buffer Layer on Electrochemical Performance of Solid Oxide Fuel Cells
}

\author{
Jung-Hoon Song ${ }^{1}$, Myung Geun Jung ${ }^{2}$, Hye Won Park², Hyung-Tae Lim²,*
}

(Received 7 May 2013; accepted 29 June 2013; published online 25 July 2013)

\begin{abstract}
A Gd-doped ceria (GDC) buffer layer is required between a conventional yttria-stabilized zirconia (YSZ) electrolyte and a La-Sr-Co-Fe-O 3 (LSCF) cathode to prevent their chemical reaction. In this study, the effect of varying the conditions for fabricating the GDC buffer layer, such as sintering temperature and amount of sintering aid, on the solid oxide fuel cell (SOFC) performance was investigated. A finer GDC powder (i.e., ultra-high surface area), a higher sintering temperature $\left(\sim 1290^{\circ} \mathrm{C}\right)$, and a larger amount of sintering aid $(\sim 12 \%)$ resulted in improved densification of the buffer layer; however, the electrochemical performance of an anode-supported cell containing this GDC buffer layer was poor. These conflicting results are attributed to the formation of $(\mathrm{Zr}, \mathrm{Ce}) \mathrm{O}_{2}$ and/or excess cobalt grain boundaries (GBs) at higher sintering temperatures with a large amount of sintering aid (i.e., cobalt oxide). A cell comprising of a cobalt-free GDC buffer layer, which was fabricated using a low-temperature process, had lower cell resistance and higher stability. The results indicate that electrochemical performance and stability of SOFCs strongly depend on fabrication conditions for the GDC buffer layer.
\end{abstract}

Keywords: Solid oxide fuel cell (SOFC); Gd-doped ceria; Sintering aid; Sol-gel spin coating

Citation: Jung-Hoon Song, Myung Geun Jung, Hye Won Park and Hyung-Tae Lim, "The Effect of Fabrication Conditions for GDC Buffer Layer on Electrochemical Performance of Solid Oxide Fuel Cells", Nano-Micro Lett. 5(3), 151-158 (2013). http://dx.doi.org/10.5101/nml.v5i3.p151-158

\section{Introduction}

Typical solid-oxide fuel-cells (SOFCs) operate at high temperatures $\left(>800^{\circ} \mathrm{C}\right)$, as a result, their lifetimes are limited by thermal degradation via coarsening of particles in the electrodes and chemical interactions between the electrolyte and electrodes, etc. Numerous approaches have been investigated to reduce the operating temperature of SOFCs for increased long-term stability and cost-efficiency [1]. Many efforts have focused on developing new electrode materials that are suitable for low temperatures $\left(<700^{\circ} \mathrm{C}\right)$, as well as minimizing the resistivity of conventional electrode materials by optimizing their microstructures and composi- tions. Conventional anode-supported SOFCs comprise $\sim 5-10 \mu \mathrm{m}$ thick YSZ electrolyte with an optimized La$\mathrm{Sr}-\mathrm{Mn}-\mathrm{O}_{3}$ (LSM)/YSZ composite cathode. However, the electrochemical performance (i.e., the catalytic activity) of the LSM/YSZ cathode is not sufficient for lowtemperature operation. Therefore, in recent years, new cathode materials with higher electrocatalytic activities have been intensively investigated for low-temperature SOFCs. Recent studies have shown that SOFCs with a $\mathrm{La}-\mathrm{Sr}-\mathrm{Co}-\mathrm{Fe}-\mathrm{O}_{3}$ (LSCF) cathode delivered about twice the power density of an LSM/YSZ composite cathode [2-4]. However, the LSCF cathode cannot be in direct contact with the YSZ electrolyte because the LSCF cathode readily reacts with the YSZ electrolyte at typ-

\footnotetext{
${ }^{1}$ Fuel Cell Project, Research Institute of Industrial Science and Technology (RIST), \#32 Hyoja-Dong, Nam-Gu, Pohang City, Gyeongbuk 790-330, Republic of Korea

${ }^{2}$ School of Nano \& Advanced Materials Engineering, Changwon National University, Changwon, Gyeongnam 641-773, Republic of Korea *Corresponding author. E-mail: htaelim@changwon.ac.kr
} 
ical SOFC operating conditions, generating an insulating $\mathrm{SrZrO}_{3}$ phase $[5,6]$. Thus, a buffer layer is required between the YSZ electrolyte and the LSCF layer in order to prevent this chemical reaction.

Gd-doped ceria (GDC) has been considered as an alternative electrolyte for low temperature SOFCs $[7,8]$, and it is also one of the most effective buffer layer materials because it does not react with the LSCF cathode materials and has a higher ionic conductivity than YSZ [9]. As a buffer layer, the GDC layer should be as thin and dense as possible. Minimized pores and a dense structure result in two advantages: (1) increased efficiency towards preventing Sr diffusion from the cathode to the electrolyte layer, and (2) higher ionic conductivity. However, GDC has poor sintering properties; therefore, it is difficult to fabricate a thin dense layer on the YSZ. Also, $(\mathrm{Zr}, \mathrm{Ce}) \mathrm{O}_{2}$-based solid solutions can form between the YSZ electrolyte and the GDC layer at $1200^{\circ} \mathrm{C}$, and have a much lower ionic conductivity than GDC and YSZ [10]. Thus, it is very important to optimize the GDC sintering temperature to obtain a dense electrolyte, minimizing the formation of a $(\mathrm{Zr}$, Ce) $\mathrm{O}_{2}$-based solid-solution insulating-phase.

In this paper, we investigated the effect of fabrication conditions, such as sintering aids (i.e., cobalt oxide) and temperature, for GDC $\left(\mathrm{Gd}_{0.1} \mathrm{Ce}_{0.9} \mathrm{O}_{2-x}\right)$ buffer layer on the electrochemical performance and stability of SOFCs. A novel gel polymeric precursor method was also used in order to fabricate a GDC layer without sintering aids at lower temperatures $[11,12]$.

\section{Experimental}

Anode-supported cells with areas of $2.5 \mathrm{~cm}^{2}$ were fabricated by applying a co-firing process with a laminated green sheet of three layers; a support, and anode functional layer, and an electrolyte $[13,14]$. The anode support layer, which comprised $\sim 900 \mu \mathrm{m}$. of yttria-stabilized zirconia (NiO+YSZ), the functional layer, which comprised 10-30 $\mu \mathrm{m}$. NiO+YSZ, and the $\sim 10 \mu \mathrm{m}$. YSZ electrolyte layer were co-sintered at $\sim 1370^{\circ} \mathrm{C}$ for $3 \mathrm{~h}$. The detail description of fabrication procedure and method can be found elsewhere [15]. Ultra-high surface area (UHSA) and low surface area (LSA) grade 10 GDC powders (Anan Kasei Co.) were used for the GDC buffer layer to prevent the formation of an insulating layer between the YSZ and LSCF layers. According to the technical data provided by Anan Kasei Co., the surface areas of LSA and UHSA GDC are $\sim 10-15$ and $\sim 30-35 \mathrm{~m}^{2} / \mathrm{g}$, respectively, which implies that UHSA GDC has a higher sintering driving force than LSA GDC at high temperatures. The mean particle diameters of UHSA and LSA were 0.29 and $0.44 \mu \mathrm{m}$, respectively. Cobalt oxide powder was added as a sintering aid to both UHSA and LSA GDC at 6 ,
9, and 12 at\% in order to investigate its enhancement of the density of the buffer layer. Six pastes consisting of powder mixtures of GDC and cobalt oxide were prepared: UHSA GDC with 6,9 and 12 at\% cobalt oxide and LSA GDC with 6,9 and 12 at\% cobalt oxide. The pastes were screen-printed on the YSZ electrolyte layer of the cells. The GDC-printed anode-supported cells were then sintered at different temperatures, i.e., $1100,1150,1200,1250$ and $1290^{\circ} \mathrm{C}$, for $3 \mathrm{~h}$. After sintering, the screen-printed GDC layer was $\sim 6 \mu \mathrm{m}$ thick. A cobalt-free GDC layer was also prepared as a reference. A low-temperature sintering process was applied using a combination of a colloidal suspension (50\%) and a gel polymeric precursor $(50 \%)[11,12]$. The YSZ surface was coated with a GDC (LSA) colloidal suspension followed by impregnating GDC polymer precursors into the colloidal coating. After drying, the coating was heated to $\sim 400^{\circ} \mathrm{C}$ to convert the polymer phase to GDC. The GDC layer was then screen-printed onto the YSZ electrolyte layers and sintered at $1100^{\circ} \mathrm{C}$ for $3 \mathrm{~h}$. The GDC layer thickness was $\sim 5 \mu \mathrm{m}$ thick. The cathode functional layer (i.e., $15 \mu \mathrm{m}$ LSCF+GDC) and cathode current collector (i.e., $\sim 40 \mu \mathrm{m}$ LSCF) were screen-printed and co-fired at $\sim 1070^{\circ} \mathrm{C}$ for $1 \mathrm{~h}$. To assess the electrochemical performance, the fabricated cell was assembled in an alumina jig using ceramic bond (AREMCO) as a sealant. The Pt paste and mesh were used for current collecting for the both electrodes. Before the test, the anode reduction was conducted with $300 \mathrm{sccm}$ of $\mathrm{H}_{2}$ with $3 \%$ humidity at $750^{\circ} \mathrm{C}$ for $3 \mathrm{~h}$. Current-voltage characteristics (i.e., I-V curves) and impedance spectra were measured at $750^{\circ} \mathrm{C}$ using Solartron 1260/1287 electrochemical instruments (AC and DC) with fuel gas in $300 \mathrm{sccm}$ of $97 \% \mathrm{H}_{2}-3 \% \mathrm{H}_{2} \mathrm{O}$ and oxidant gas in $1000 \mathrm{sccm}$ of air. The impedance measurements were conducted in the frequency range $\sim 0.1-100 \mathrm{kHz}$ with a signal amplitude of $100 \mathrm{mV}$ under open-circuit conditions. The detail description of cell testing procedure and method can be found elsewhere [15]. Microstructural and compositional analyses were conducted on the fabricated anode-supported cells via field-emission scanning electron microscopy (FE-SEM) with an energy-dispersive X-ray (EDX).

\section{Results and discussion}

\section{GDC microstructure as a function of particle size, sintering aid and temperature}

Figure 1 shows photographic images of the anodesupported cells with the GDC buffer layers that were applied under the various conditions described in Section 2. It is evident that the GDC layer becomes darker with increasing amounts of cobalt oxide, which is black, and becomes increasingly yellow with increasing sintering temperature. This color change with sintering 


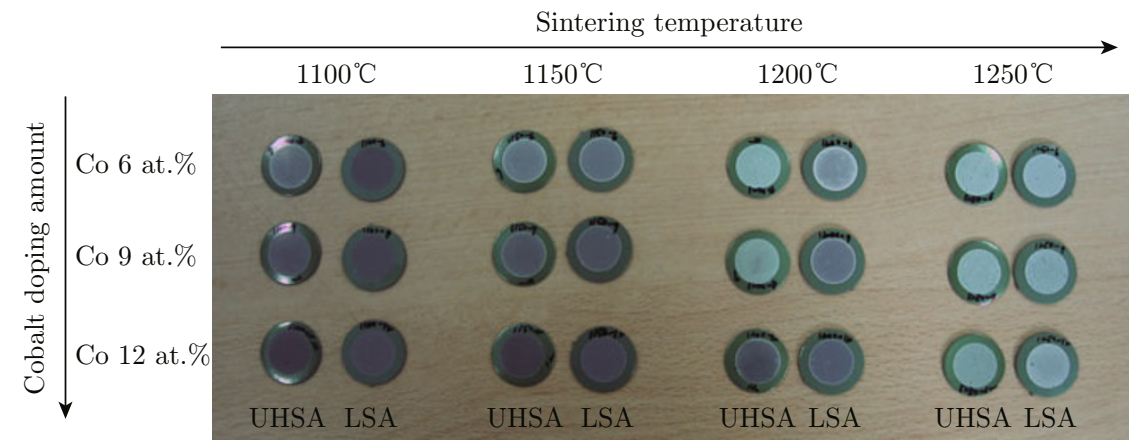

Fig. 1 Photographic images of button cells with GDC buffer layers fabricated with varying GDC particle sizes, sintering temperatures, and amounts of cobalt oxide.

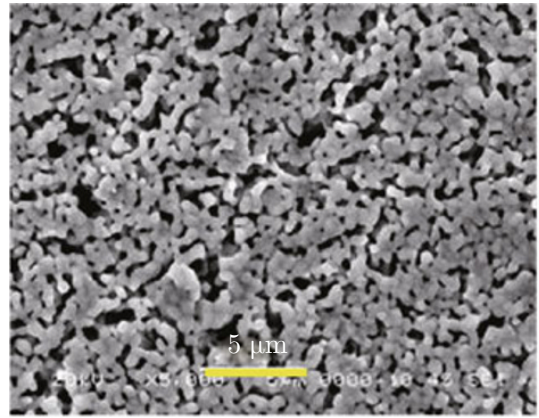

(a)

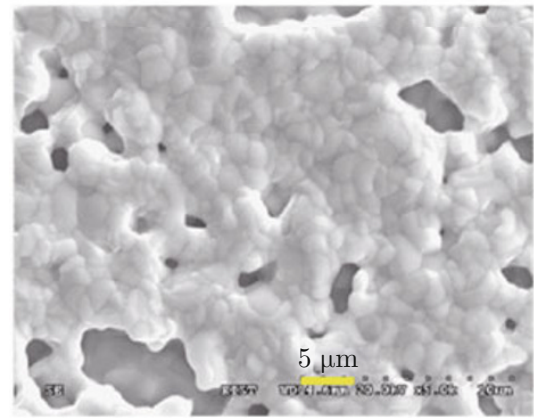

(d)

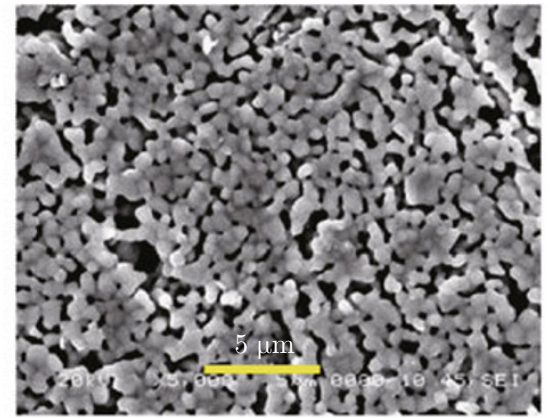

(b)

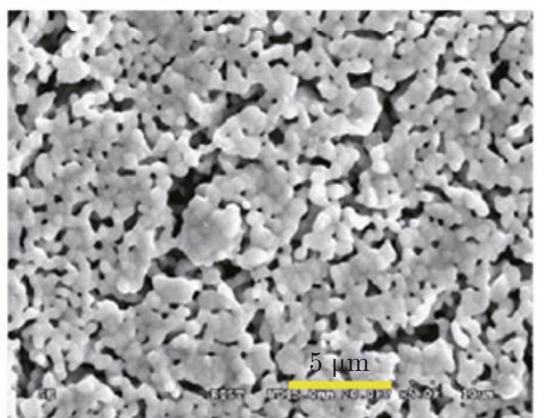

(e)

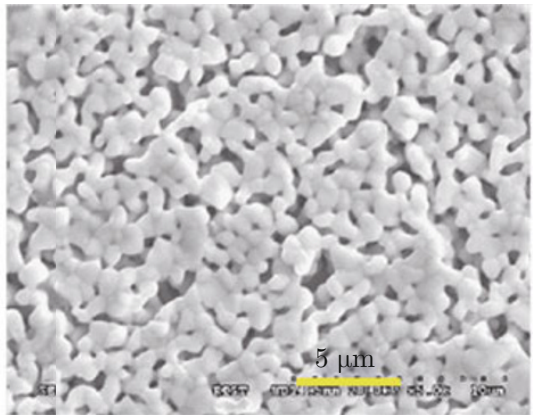

(c)

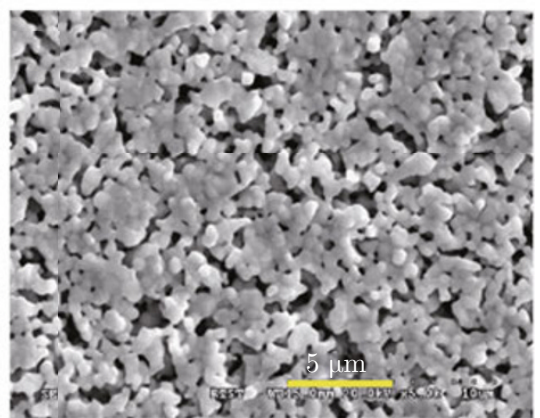

(f)

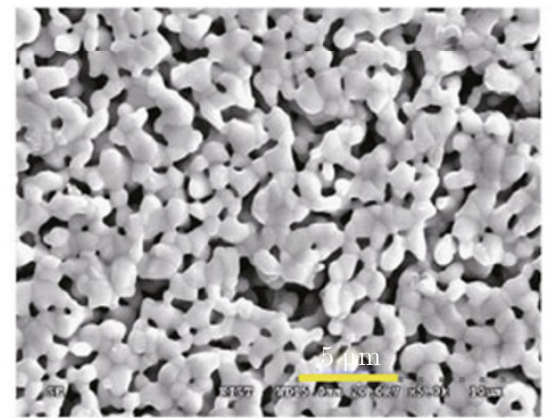

(g)

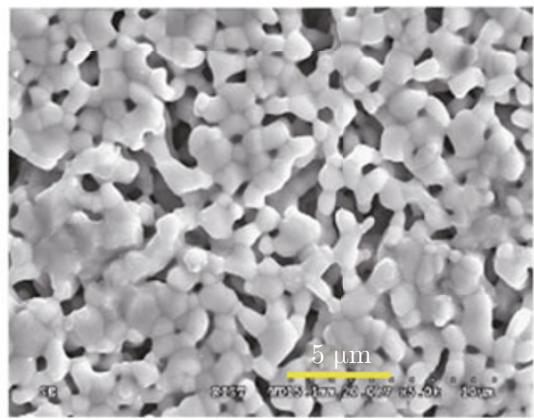

(h)

Fig. 2 Micrographs of the surface of the GDC layer with added cobalt oxide as a function of particle size, sintering aid, and temperature: (a) 6 at\% cobalt, UHSA GDC $\left(1250^{\circ} \mathrm{C}\right)$; (b) 12 at\% cobalt, UHSA GDC $\left(1250^{\circ} \mathrm{C}\right)$; (c) 6 at\% cobalt, UHSA $\operatorname{GDC}\left(1290^{\circ} \mathrm{C}\right)$; (d) $12 \mathrm{at} \%$ cobalt, UHSA GDC $\left(1290^{\circ} \mathrm{C}\right)$; (e) 6 at\% cobalt, LSA GDC $\left(1250^{\circ} \mathrm{C}\right.$; (f) 12 at\% cobalt, LSA GDC $\left(1250^{\circ} \mathrm{C}\right)$; (g) 6 at\% cobalt, LSA GDC $\left(1290^{\circ} \mathrm{C}\right)$; (h) 12 at\% cobalt, LSA GDC $\left(1290^{\circ} \mathrm{C}\right)$.

temperature may be attributed to differences in the solubility of cobalt oxide in the GDC grains. Using highresolution transmission electron microscopy (HRTEM), Zhang et al. characterized the microstructure of GDC with added cobalt oxide with sintering between $\sim 800$ and $1150^{\circ} \mathrm{C}$ [16]. They found that precipitates of cobalt oxide initially form clusters at low sintering temperatures, which are strongly segregated at the grain bound- 
aries (GBs) as a result of their low solubility in GDC. At higher sintering temperatures, the precipitates were regularly distributed as isolated particles in the triple junctions, which gradually grew with prolonged holding time. The cobalt GB concentration also increased with increasing sintering temperature, which is a result of grain growth and/or pre-wetting. Thus, the redistribution of cobalt and cobalt excess at GBs at high temperatures may be the cause of the color-changing behavior of the cobalt-added GDC layer.

Figure 2(a)-(h) show micrographs of the surfaces of cobalt-added GDC buffer layers that were fabricated under various conditions, i.e., including 6 or 12 at\% Co, either UHSA or LSA GDC, and $1250^{\circ} \mathrm{C}$ or $1290^{\circ} \mathrm{C}$ sintering temperature. As expected, a larger amount of cobalt oxide and higher surface area and sintering temperature resulted in improved grain connectivity and a denser GDC microstructure: The optimal microstructure was achieved at a sintering temperature of $1290^{\circ} \mathrm{C}$ using UHSA-grade powder and $\sim 12$ at\% sintering aid, as shown in Fig. 2(d).

\section{Electrochemical performance as a function of GDC particle size, sintering aid and tempera- ture}

The power density (i.e., cell voltage) was measured at $0.5 \mathrm{~A} / \mathrm{cm}^{2}$ and $750^{\circ} \mathrm{C}$ for cells containing GDC layers that were fabricated under a variety of conditions; the results are shown in Fig. 3 and Table 1. High power densities were observed when the GDC layers were sintered between $\sim 1200$ and $1290^{\circ} \mathrm{C}$. It was expected that the highest power density would be obtained using the GDC layer with the highest microstructural density (i.e., the GDC layer that was fabricated with UHSAgrade GDC and 12 at\% cobalt oxide at a sintering temperature of $\sim 1290^{\circ} \mathrm{C}$ ) because the denser buffer layer should have higher ionic conductivity and most effectively protect the electrolyte from $\mathrm{Sr}$ diffusion. However, the power density tests revealed that the electrochemical performance did not linearly correlate with the microstructure (i.e., density) of the GDC buffer layer. Surprisingly, the cell with the densest buffer layer had a poor electrochemical performance $(\sim 0.343$
$\mathrm{W} / \mathrm{cm}^{2}$ ). With sintering at $\sim 1200^{\circ} \mathrm{C}$, the power density increased with increasing amounts of cobalt oxide, which is probably the result of densification of the GDC buffer layer by the sintering aid. In contrast, at higher sintering temperatures $\left(\sim 1290^{\circ} \mathrm{C}\right)$, the power density decreased with increasing amounts of cobalt oxide, which is probably caused by formation of excess cobalt oxide at GBs at higher temperatures [16]. In this case (the high temperature sintering), the negative effect of GB excess becomes dominant rather than the positive effect of densification with increasing the amount of cobalt oxide. Thus, the electrochemical performances of SOFCs are not simply proportional to the densification of the buffer layer. Accordingly, the sintering temperature should be carefully optimized for each combination of conditions (i.e., particle size, cobalt oxide content, etc.).

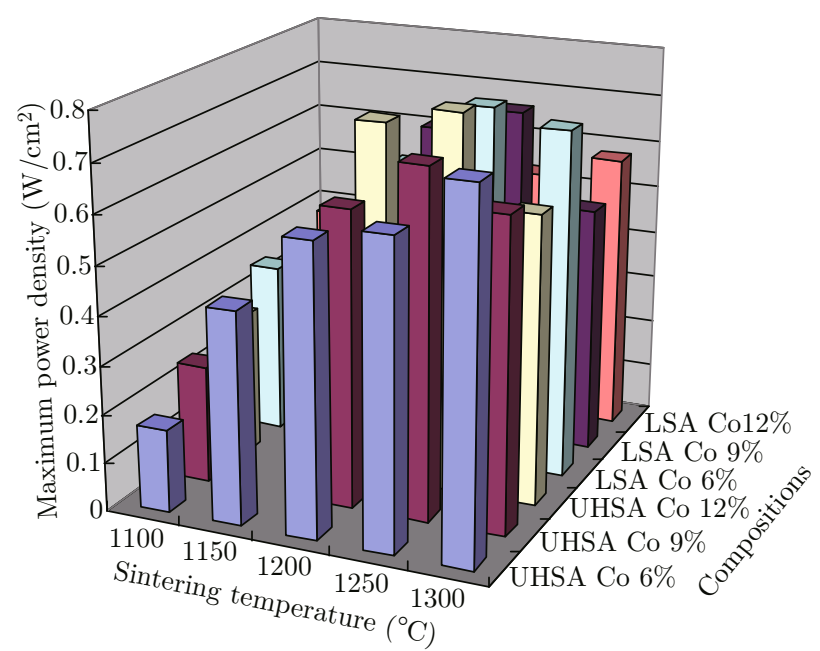

Fig. 3 Plots of power density measured at $750^{\circ} \mathrm{C}$ and 0.5 $\mathrm{A} / \mathrm{cm}^{2}$ as a function of GDC particle size, sintering temperature, and amount of cobalt oxide.

Figure 4 shows the impedance spectra of three selected samples measured at $750^{\circ} \mathrm{C}$ under open-circuit conditions. The samples were sintered at different sintering temperatures (i.e., 1200,1250 and $1290^{\circ} \mathrm{C}$ ). All three samples were synthesized with LSA-grade GDC and 6 at\% cobalt oxide. Figure 4 shows that the

Table 1 Power density $\left(\mathrm{W} / \mathrm{cm}^{2}\right)$ at $750^{\circ} \mathrm{C}$ and $0.5 \mathrm{~A} / \mathrm{cm}^{2}$ of SOFCs containing GDC layers that were fabricated using various conditions.

\begin{tabular}{|c|c|c|c|c|c|c|}
\hline \multirow{3}{*}{ Sintering temperature $\left(^{\circ}\right)$} & \multicolumn{6}{|c|}{ Power density $\left(\mathrm{W} / \mathrm{cm}^{2}\right)$} \\
\hline & \multicolumn{3}{|c|}{ LSA-grade GDC } & \multicolumn{3}{|c|}{ UHSA-grade GDC } \\
\hline & 6 at $\%$ & 9 at $\%$ & 12 at $\%$ & 6 at\% & 9 at $\%$ & 12 at $\%$ \\
\hline 1100 & 0.235 & & 0.262 & 0.112 & 0.172 & 0.204 \\
\hline 1150 & 0.416 & 0.426 & 0.423 & 0.302 & & 0.323 \\
\hline 1200 & 0.423 & 0.430 & 0.433 & 0.376 & 0.426 & 0.499 \\
\hline 1250 & 0.499 & 0.479 & 0.350 & 0.422 & 0.450 & 0.500 \\
\hline 1290 & 0.489 & 0.333 & 0.385 & 0.498 & 0.419 & 0.343 \\
\hline
\end{tabular}




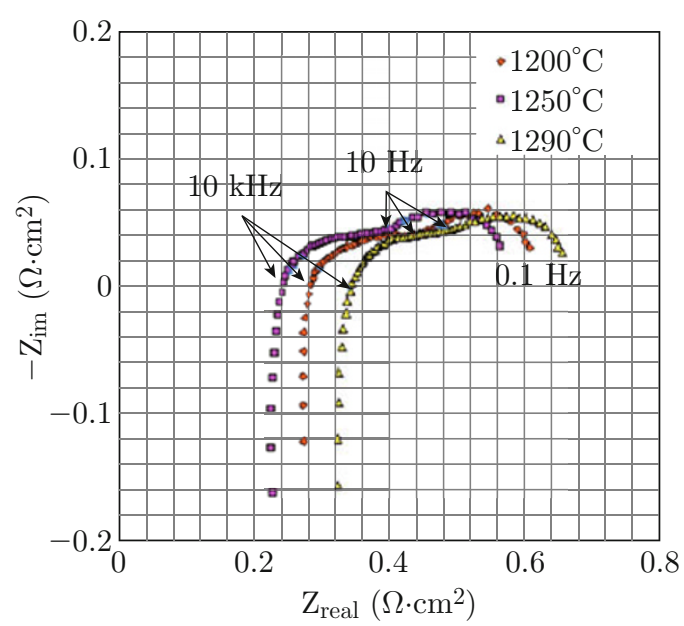

Fig. 4 Impedance spectra under open-circuit conditions at $750^{\circ} \mathrm{C}$ as a function of sintering temperature of the GDC buffer layer (LSA-grade GDC and 6 at\% cobalt oxide).

non-ohmic polarization resistance, which is represented by the first and second semicircles, was similar for all three samples. In contrast, the ohmic resistance was dependent on the GDC sintering temperature, and increases in the order of the sintering temperature (i.e., $\left.1250<1200<1290^{\circ} \mathrm{C}\right)$. Note that the frequency that corresponds to the intercept of the impedance arc on the real axis is $\sim 10^{4} \mathrm{~Hz}$ for all three cases, which confirms that it is valid to compare the real axis intercepts. EDX analyses indicate that $(\mathrm{Zr}, \mathrm{Ce}) \mathrm{O}_{2}$-based solid solutions formed at the interface of the GDC layer and the YSZ electrolyte, regardless of the sintering temperature (Fig. 5). This solid solution is an insulating layer that has a low ionic conductivity $[7,10]$. Nguyen et al. studied a GDC interlayer between an LSCF cathode and a scandia-stabilized zirconia (ScSZ) electrolyte, which was deposited by screen-printing [17]. Similar to our results, the best electrochemical performance was obtained with a GDC sintering temperature of $\sim 1200^{\circ} \mathrm{C}$, whereas sintering at $\sim 1300^{\circ} \mathrm{C}$ resulted in poor electrochemical performance. The critical factors for the decrease in the electrochemical performance with increasing sintering temperature were assessed and it was concluded that the development of solid solutions, i.e., $(\mathrm{Zr}, \mathrm{Ce}) \mathrm{O}_{2}$, was minimal between $1100^{\circ} \mathrm{C}$ and $1200^{\circ} \mathrm{C}$, but increased significantly above $1200^{\circ} \mathrm{C}$. Based on these results, the increase in ohmic resistance above $1250^{\circ} \mathrm{C}$ shown in Fig. 4 is attributed to the effects of the solid solution, which become significant above $1250^{\circ} \mathrm{C}$ in our experiments. Even though it is difficult to determine the exact thickness of the solid solution for each case shown in Fig. 5, it is evident that a higher sintering temperature results in more solid solution between the GDC layer and YSZ electrolyte. In addition, as mentioned above, the development of excess cobalt oxide at GBs as resistive impurities could also be a reason for the higher resistance at higher temperatures. It should be noted that the optimized sintering tempera- ture could differ from $1250^{\circ} \mathrm{C}$, depending on the particle size and amount of sintering aid, as shown in Table 1. This is because all the three effects (GDC densification, ( $\mathrm{Zr}, \mathrm{Ce}) \mathrm{O}_{2}$-solid solution formation and cobalt excess at GBs) complexly occur as the sintering temperature increases. In summary, a higher sintering temperature is favorable for the densification of the GDC layer, but the sintering temperature must be chosen to optimize electrochemical performance as well.

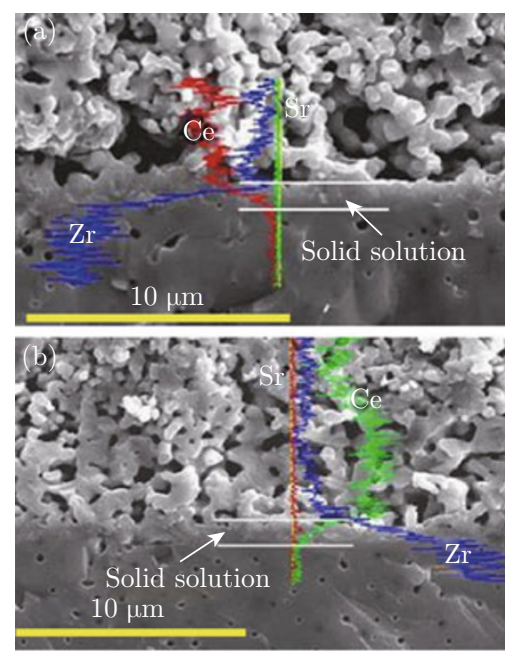

Fig. 5 SEM images and EDS Zr and Ce profiles of GDC layer sintered at (a) $1100^{\circ} \mathrm{C}$ and (b) $1290^{\circ} \mathrm{C}$. Note that the $(\mathrm{Ce}-\mathrm{Zr}) \mathrm{O}_{2}$ solid solution is formed even at low sintering temperatures $\left(\sim 1100^{\circ} \mathrm{C}\right)$.

The effect of the addition of cobalt on the stability of SOFCs was also investigated. A long-term (five-day) operating test was conducted on the cells, which contained a GDC layer fabricated from LSA-grade GDC with $\sim 12$ at $\%$ cobalt oxide. Figure $6(\mathrm{a})$ and (b) show the power density and impedance spectra, respectively, as a function of operating time. The electrochemical performance rapidly degraded over the initial three days and then more slowly degraded over the final two days. On the basis of the impedance results, this reduction in power density is primarily attributed to the increase in ohmic resistance as a function of time. As mentioned above, cobalt can be segregated at GBs as a result of low solubility in GDC. Additionally, cobalt precipitates grow over time and the GB concentration increases with temperature as a result of grain growth [16]. Thus, it can be deduced that the excess of cobalt GBs increased over the five days of the experiment, resulting in increased ohmic resistance.

To clarify the effect of the sintering temperature and the addition of cobalt on the cell performance, cobalt-free reference cells were fabricated with GDC layers that were made using a novel low-temperature $\left(\sim 1100^{\circ} \mathrm{C}\right)$ processing and screen-printing method, as described in Section 2. Figure 7(a) and (b) show the 

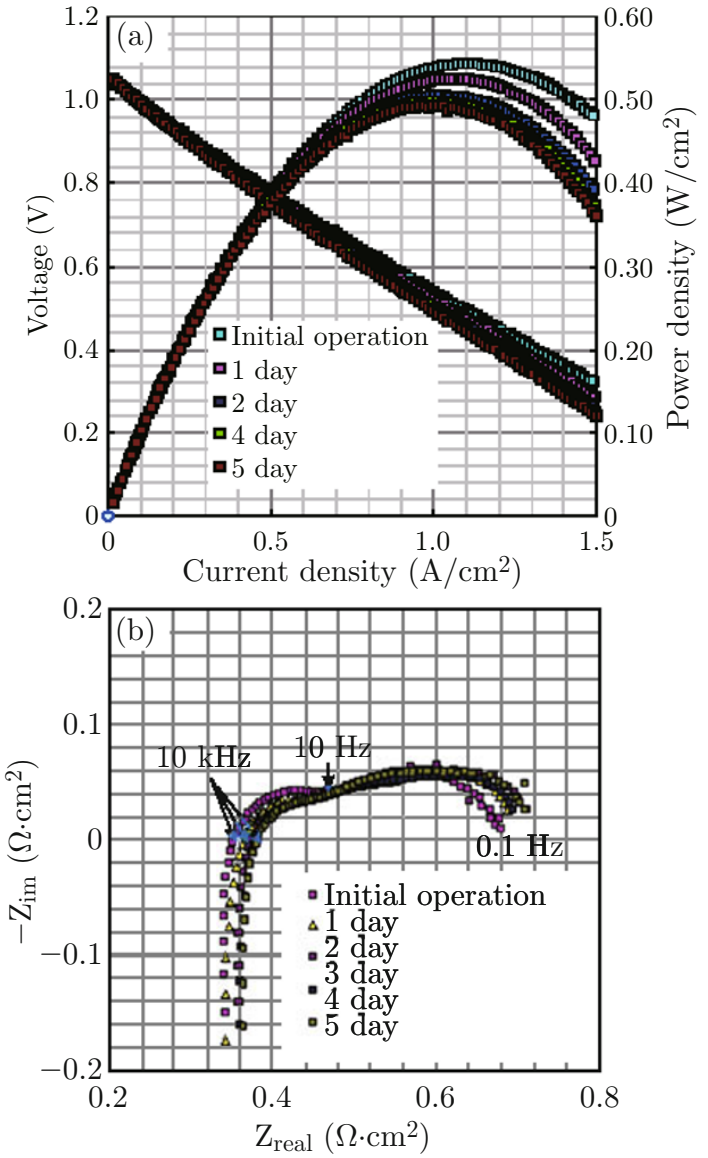

Fig. 6 (a) $I-V$ curves and (b) impedance spectra under open-circuit conditions at $750^{\circ} \mathrm{C}$ as a function of time. The GDC buffer layer was sintered at $1290^{\circ} \mathrm{C}$ with LSA-grade GDC and 6 at $\%$ cobalt oxide.

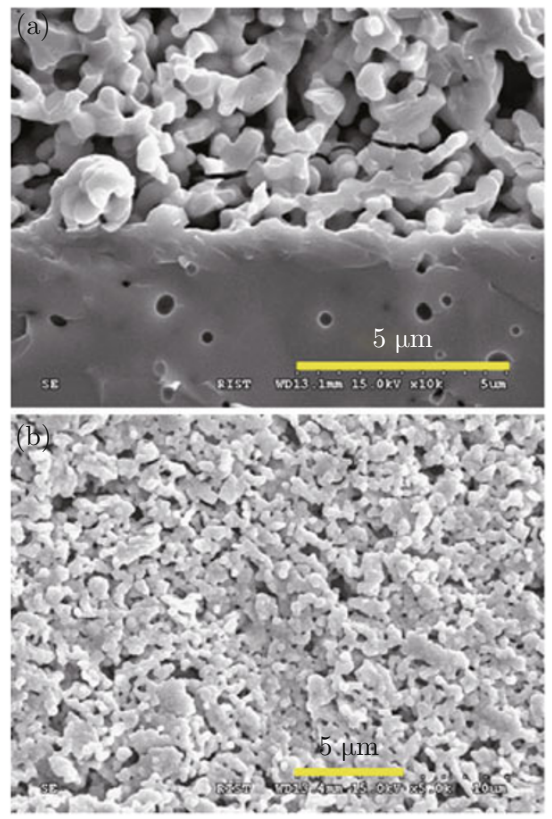

Fig. 7 (a) Micrograph of (a) the cross-section and (b) the surface of the GDC layer that was fabricated using a combination of a GDC colloidal suspension and polymer precursors, and sintered at $\sim 1100^{\circ} \mathrm{C}$. cross section and the surface SEM micrograph of the cobalt-free GDC layer, respectively. The corresponding $\mathrm{I}-\mathrm{V}$ characteristics and impedance spectra are shown in Fig. 8(a) and (b), respectively. Compared to the cobaltadded cells, the power density was improved $(\sim 0.86$ $\mathrm{W} / \mathrm{cm}^{2}$ ) although the density of the GDC layer was not higher. The impedance data indicate that this performance improvement was mainly attributed to a decrease in the ohmic resistance (from $\sim 0.35$ to $\sim 0.16$ $\left.\Omega \cdot \mathrm{cm}^{2}\right)$. In this case, the ohmic resistive factors, such as $(\mathrm{Zr}, \mathrm{Ce}) \mathrm{O}_{2}$-solid solution and the excess of cobalt GBs were minimized and removed because the GDC was sintered at the lower temperature $\left(\sim 1100^{\circ} \mathrm{C}\right)$ without cobalt oxide [17]. Additionally, the degradation rate became less in the cobalt-free cells. The slight degradation (the increase in both ohmic and non-ohmic polarization resistance) was probably attributed to typical degradation factors such as the formation of $\mathrm{SrZrO}_{3}$ on the surface of the YSZ electrolyte [7], Sr segregation in the LSCF cathode [18] and/or Ni coarsening [19].

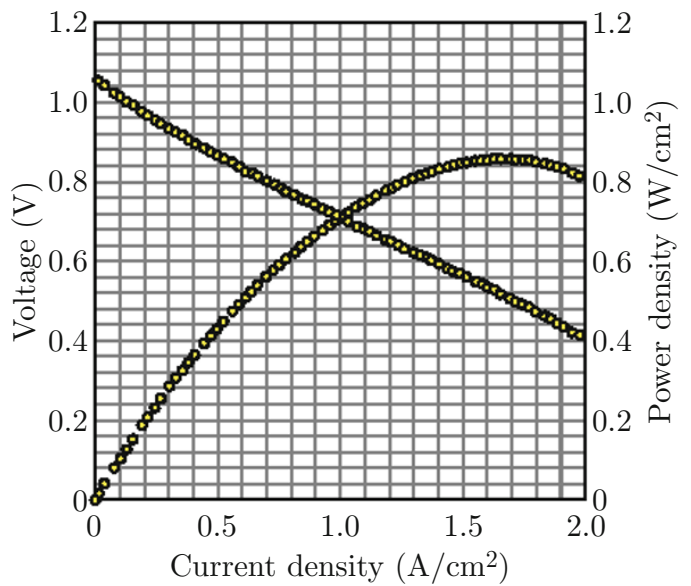

(a)

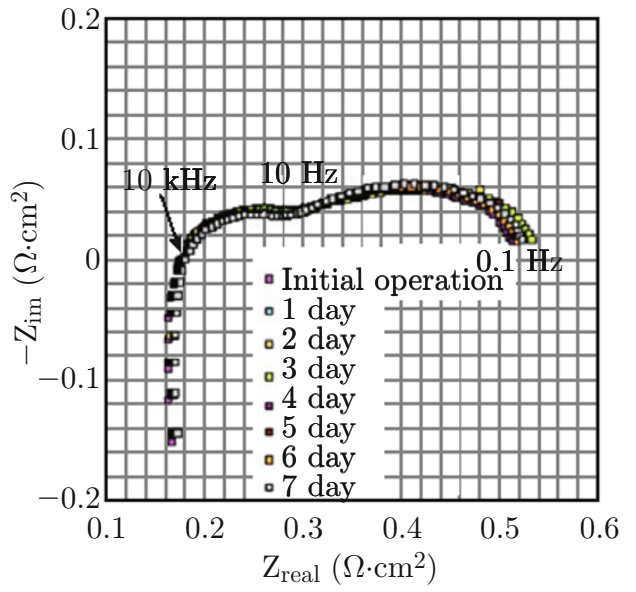

(b)

Fig. 8 (a) $I-V$ curves at the initial state and (b) impedance spectra under open-circuit conditions at $750^{\circ} \mathrm{C}$ as a function of time. The GDC buffer layer was fabricated using using a combination of a GDC colloidal suspension and polymer precursors, and sintered at $\sim 1100^{\circ} \mathrm{C}$. 
From these results, it is evident that the solid solution and the cobalt GB segregation have more influence on SOFC performance and stability than the GDC density. Therefore, GDC fabrication conditions should be carefully optimized to minimize the negative effects, such as the GDC/YSZ chemical reaction and the excess cobalt GB, while maximizing the GDC density.

\section{Conclusion}

The present study shows that the electrochemical performances of SOFCs with LSCF cathodes is strongly dependent on the fabrication conditions of the GDC layer, such as sintering temperature and amount of added sintering aid. Several attempts were made to optimize the conditions with respect to the SOFC electrochemical performance and the densification of the GDC buffer layer. It was determined that the density of the GDC buffer is improved by increasing the sintering temperature and amount of sintering aid; however, the cell resistance and the rate of cell degradation increase under these conditions. This implies that the density of the buffer layer does not linearly correlate with the electrochemical performance as a result of negative secondary effects such as the formation of $(\mathrm{Zr}, \mathrm{Ce}) \mathrm{O}_{2}$ and excess cobalt GBs, which function as resistive impurities and increase the ohmic resistance. In the case of the cobalt free GDC made using a low temperature processing, the cell performance and stability were significantly improved by decreasing the ohmic resistance originated from the solid solution and the cobalt GB segregation. Thus, fabrication conditions, such as the amount of sintering aid and the sintering temperature, should be carefully optimized for a GDC buffer layer having high performance and stability.

\section{Acknowledgments}

This research was supported by Basic Science Research Program through the National Research Foundation of Korea (NRF) funded by the Ministry of Education, Science and Technology (2012013782) and research funds of Changwon National University in 20122013.

\section{References}

[1] J. P. P. Huijsmans, F. P. F Berkel and G. M. Christie, "Intermediate temperature SOFC-a promise for the 21st century", J. Power Sources 71(10), 107-110 (1998). http://dx.doi.org/10.1016/ S0378-7753 (97) 02789-4

[2] A. Mai, V. A. C. Haanappel, U. Uhlenbruck, F. Tietz and D. Stöver, "Ferrite-based perovskites as cathode materials for anode-supported solid oxide fuel cells: Part I. Variation of composition", Solid State Ion- ics 176(15-16), 1341-1350 (2005). http://dx.doi.org/ 10.1016/j.ssi.2005.03.009

[3] Y. Teraoka, H. M. Zhang, K. Okamoto and N. Yamazoe, "Mixed ionic-electronic conductivity of $\mathrm{La}_{1-x} \mathrm{Sr}_{x} \mathrm{Co}_{1-y} \mathrm{FeyO}_{3-\delta}$ perovskite-type oxides", Mater. Res. Bull. 23(1), 51-58 (1998). http://dx.doi. org/10.1016/0025-5408(88) 90224-3

[4] S. P. Scott, D. Mantzavinos, A. Hartley, M. Sahibzada and I. S. Metcalfe, "Reactivity of LSCF perovskites", Solid State Ionics 152-153, 777-781 (2002). http://dx. doi.org/10.1016/S0167-2738(02)00327-2

[5] A. Mai, M. Becker, W. Assenmacher, F. Tietz, D. Hathiramani, E. Ivers-Tiffee, D. Stover and W. Mader, "Time-dependent performance of mixedconducting SOFC cathodes", Solid State Ionics 177(19-25), 1965-1968 (2006). http://dx.doi.org/ $10.1016 / j . s s i .2006 .06 .021$

[6] H. Uchida, S. Arisaka and M. Watanabe, "High performance electrode for medium-temperature solid oxide fuel cells $\mathrm{La}(\mathrm{Sr}) \mathrm{CoO}_{3}$ cathode with ceria interlayer on zirconia electrolyte", Electrochem. Solid. St. 2(9), 428430 (1999). http://dx.doi.org/10.1149/1.1390860

[7] H. L. Tuller and A. S. Nowick, "Doped ceria as a solid oxide electrolyte", J. Electrochem. Soc. 122(2), 255259 (1979). http://dx.doi.org/10.1149/1.2134190

[8] B. C. H. Steele, "High conductivity solid ionic conductors", (T. Takahashi, Eds.), World Scientific, Singapore (1989).

[9] M. Mogensen, N. M. Sammes and G. A. Tompsett, "Physical, chemical and electrochemical properties of pure and doped ceria", Solid State Ionics 129(1-4), 63-94 (2000). http://dx.doi.org/10.1016/ S0167-2738(99)00318-5

[10] A. Tsoga, A. Gupta, A. Naouidis and P. Nikolopoulos, "Gadolinia-doped ceria and yttria stabilized zirconia interfaces: regarding their application for SOFC technology", Acta Materialia 48(1819), 4709-4714 (2000). http://dx.doi.org/10.1016/ S1359-6454(00) 00261-5

[11] V. Petrovsky, T. Suzuki, P. Jasinski and H. U. Anderson, "Low-temperature processed anode for solid oxide fuel cells", Electrochem. Solid. St. 8(7), A341-A343 (2005). http://dx.doi.org/10.1149/1.1928237

[12] V. Petrovsky, T. Suzuki, P. Jasinski, T. Petrovsky and H. U. Anderson, "Low-temperature processing of thin-film electrolyte for electrochemical devices", Electrochem. Solid. St. 7(6), A138-A139 (2004). http:// dx.doi.org/10.1149/1.1697904

[13] Jung-Hoon Song, Sun-Il Park, Hwan Moon, SangHoon Hyun, Seongjae Boo, Nigel M. Sammes and HoSung Kim, "Fabrication and characterization of anodesupported planar solid oxide fuel dell manufactured by a tape casting process", J. Fuel Cell Sci. Tech. 5(2), 021003-1 (2008). http://dx.doi.org/10.1115/ 1.2885401

[14] J. H. Song, S. I. Park, J. H. Lee and H. S. Kim, "Fabrication characteristics of an anode-supported thin-film electrolyte fabricated by the tape casting method for IT-SOFC", J. Mater. Process. Tech. 198(1-3), 414-418 (2008). http://dx.doi.org/10.1016/j.jmatprotec. 2007.07 .030 
[15] Y. M. Park, H. J. Lee, H. Y. Bae, J. S. Ahn and H. Kim, "Effect of anode thickness on impedance response of anode-supported solid oxide fuel cells", Int. J. Hydrogen Energy 37(5), 4394-4400 (2012). http://dx. doi.org/10.1016/j.ijhydene.2011.11.152

[16] Z. Zhang, W. Sigle, M. Ruhle, E. Jud and L. J. Gauckler, "Microstructure characterization of a cobalt-oxide-doped cerium-gadolinium-oxide by analytical and high-resolution TEM", Acta Mater. 55(8), 2907-2917 (2007). http://dx.doi.org/10.1016/j. actamat.2006.12.039

[17] T. L. Nguyen, K. Kobayashi, T. Honda, Y. Iimura, K. Kato, A. Neghisi, K. Nozaki, F. Tappero, K. Sasaki, H. Shirahama, K. Ota, M. Dokiya and T. Kato, "Preparation and evaluation of doped ceria interlayer on supported stabilized zirconia electrolyte SOFCs by wet ceramic processes", Solid State Ionics 174(1-4), 163-174 (2004). http://dx.doi.org/10.1016/j.ssi. 2004.06 .017

[18] S. P. Simmer, M. D. Anderson, M. H. Engelhard and J. W. Stevenson, "Degradation Mechanisms of La-Sr-Co-Fe-O 3 SOFC Cathodes", Electrochem. Solid. St. 9(10), A478-A481 (2006). http://dx.doi.org/10. $1149 / 1.2266160$

[19] H. Yokokawa, H. Tu, B. Iwanschitz and A. Mai, "Fundamental mechanism limiting solid oxide fuel cell durability", J. Power Sources 182(2), 400-412 (2008). http://dx.doi.org/10.1016/j.jpowsour. 2008.02. 016 